
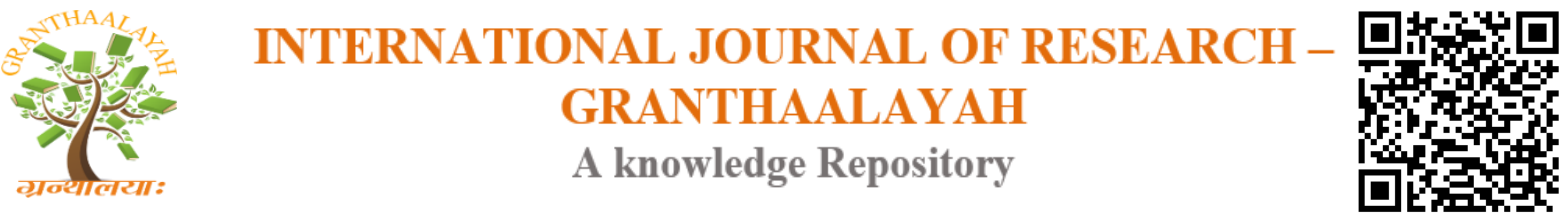

Social

\title{
UNDERSTANDING YOGASUTRA: A FRAMEWORK FOR ECOLOGICAL VIRTUE ETHICS
}

\author{
Dr. P.S. Sreevidya ${ }^{* 1}$ \\ ${ }^{*}$ Independent Researcher, India
}

\begin{abstract}
This is an endeavor to seek the possibilities of the application of ethical principles of yoga in present day of ecological issues. The relevance of this research paper is evident from the fact that ecological issues are not only scientific but also an ethical and this research paper is reliable and informative in the extent that it seeks to challenge the existing relationship between human beings and nature with the description of the present crisis of ecology as a crisis of human-nature relationship. To talk of ecological issues signifies that most of the issues may occur because of the attitude and behavior patterns of man towards environment. The confluence of ethical principles of yoga and ecology offer profoundly relevant response to the ecological issues and brings forth an ecological virtue ethics, which care for all natural entities with main focus of the relationship between man and environment. It offer systematic framework for understanding the traits of character and types of action that cause problems for environment. Yoga approach on ecology is intrinsic in nature, which includes moral expansionism that tries to expand outward from human centered ethics towards animals and sentient life in general. All life forms of plants and animals are interrelated and have an intrinsic value. Ethical principles of yoga give greater importance to the attitude of the mind rather than on postulation of the elaborate theories of what is right and wrong. So the virtues of yoga ethics would be used as a remedy towards changing an attitude of the common man towards his environment.
\end{abstract}

Keywords: Yoga; Yama; Niyama; Virtue Ethics; Ecological Virtue Ethics.

Cite This Article: Dr. P.S. Sreevidya. (2017). "UNDERSTANDING YOGASUTRA: A FRAMEWORK FOR ECOLOGICAL VIRTUE ETHICS." International Journal of Research Granthaalayah, 5(7), 270-279. https://doi.org/10.29121/granthaalayah.v5.i7.2017.2133.

\section{Introduction}

The world facing unprecedented set of ecological issues and most of them are the result of man's behavior patterns and attitude towards nature. It indicates that the problem of ecology is not only the scientific but also an ethical, which require broader philosophical understanding of human beings are the creatures of nature, embedded in life cycles and dependent on ecosystems. So it is the high time for the people to become conscious and aware of the understanding of ecological problems and necessary measures to reduce these problems. Yoga is one of the most popular and 
revolutionized philosophical systems of India founded on ethical teachings. Most of the yoga practitioners today concentrate on asana, pranayama and smaller per cent venture into the more advanced stages of prathyahara, dharana, and dhyana, but everyone chooses to forget about the all-important yama and niyama, which constitute the foundation stone of entire system of yoga and it is referred as the ten commandments of yoga. Patanjali fabricates a scheme of eight accessories or eight limbs with the technical designation called astangayoga. The first two limbs are ethical, the next three are physical and the last three are psychological; culminating in spiritual consequences. The yamas comprise the restraints apply to individual discipline, while the niyamas are personal observances. Together they form a systematic collection of rules of conduct guiding ethical behavior or code of ethics. The ethical principle of yoga lays emphasis on right conduct as the means of development of the personality of an individual. Hence in a way the ethics of yoga is the ethics of right action. Here, the ethics of yoga spell out the dimension of virtue ethics and further it goes to the extent of ecological virtue ethics, more clearly putting virtues into action. Ecological virtue ethics appeals to the development of ecologically conscious character. Ecological virtues are proper dispositions or character traits for human beings to have regarding their interactions and relationships with ecosystem. In this extent, the ethical principles of yoga bring forth ecological virtue ethics which offer systematic framework for understanding the traits of character and types of actions that cause problems for us and others. Main ecological virtues of yoga system are:-reverence for life, responsibility, frugality, compassion and justice for all. It focuses on the relationship between man and nature. These virtues would be used as remedy towards changing the attitude of the individuals towards nature.

\section{Yogasutra - A Structural Analysis}

Yoga as a system of thought and practice has a primary reference to the philosophical system that flows from the teaching of the ancient Indian yoga philosopher, Patanjali. Patanjali is believed to have compiled the first systematic text on yoga between the $6^{\text {th }}$ and $2^{\text {nd }}$ century B.C. He collected the concepts and techniques scattered in the Vedic and Upanishadic literature and framed them into famous Yogasutra. Yogasutra is composed in the form of extremely terse and self-contained aphorisms or sutras. Sutra literally means 'thread'. It is a line of thought or a sentence that ties many ideas together. Yogasutra outlines the sovereign path of rajayoga, is composed of total 196 sutras or aphorisms. These sutras are structured around four padas or segments as detailed below.
1) Samadhipada
2) Sadhanapada
3) Vibhutipada and
4) Kaivalyapada

\subsection{Samadhipada}

The first segment of Yogasutra gives a broad outline of the yogic ways and its aims. It is called samadhipada or the part dealing with meditative absorption and explains the aim of the science of yoga. This part composed of 51 sutras, contemplates on the absolute true consciousness or isvara, the supreme purusa, unaffected by any afflictions or by any inner impressions of desires and delineates the problems of an individual soul. The major topics discussed in samadhipada are the purpose of yoga, five kinds of disturbances, two requirements for deliverance, two kinds 
of consciousness, obstacles and their accompaniments, the need and aids of single mindedness and the layers of veils.

The samadhipada begins with the understanding of human thought process or vrittis, which deter us from realizing our true selves. The samadhipada advises the restraint of such natural workings of the mind and discusses the problem encountered while trying to harness it. Here again the best methods of conquering these impediments are also discussed. Gradually one's mastery in concentration extends from the primal atom to the greatest magnitude. This culmination of meditation is called samadhi. In the end, the yogi gain ritambarapranja, which is pure wisdom, whose means of knowledge unlike any other are drawn solely from the awareness of the absolute. At this stage, the yogi becomes totally detached from all the four sheaths of foodstuff sheath (annamayakosa), energy sheath (pranamayakosa), mind sheath (manomayakosa), and wisdom sheath (vinjanamayakosa). His consciousness merely remains attached with the purely spiritual sphere of the bliss sheath anandamayakosa. This is the state which is defined as nirbija samadhi, when all seeds of earthly impressions are erased from the yogi's consciousness.

\subsection{Sadhanapada}

Second segment of Yogasutra is known as sadhanapada explaining the means to reach the goal. Sadhana is the Sanskrit word for practice or discipline. The major topics of discussion are the aims of practice, the five hindrances, the avoidance of evil results, association of the soul and body, the way to destroy illusion, the seven final insights, eight limbs of yoga, five abstentions, effortless postures, relaxation of breathing, and retraction of senses. These points are elaborated in fifty five verses.

After explaining the aims of yoga in the first part, the second part of the Yogasutra is devoted to the process of action. Here the author outlines two forms of yoga, kriyayoga and astangayoga. Kriyayoga sometimes called karmayoga, the yoga of selfless action and service. The karmas bear fruits of pleasure and pain caused by merit and demerit. Astangayoga describes the eight limbs, they together constitute rajayoga. By the practice of eight limbs of yoga, the impurities dwindle away and there dawns the light of wisdom, leading to discriminative discernment. Sadhanapada establishes the aim of yoga as bring the control of the cittavrittis to attain the highest union. The practice of astangayoga is the means to achieving this union.

This section of Yogasutra identifies ignorance and other obstacles to meditation as a major cause of inability to naturally merge with the absolute, and to this end it advances to eradicate all such klesas by practicing the eight limbs of yoga and benefiting from their advantages. Five afflictions are stated thus; ignorance, egoism, desire, aversion and attachment.

(i) Ignorance: - Ignorance is first of these afflictions. It is the fundamental cause of the four forms of afflictions sutra No. 4, lists four degrees of ignorance:-

- Dormant afflictions are those that have not yet awakened.

- Extenuated afflictions are those that are subdued through yoga.

- Interrupted afflictions are those that are over powered by some antagonistic afflictions.

- Overt afflictions are those that are expressed when the causative factor is present. 
The yoga expert will get rid of afflictions by removing their root namely ignorance. Ignorance is the fundamental cause or the root cause or the soil of all other afflictions. Sutra No.5 of the Yogasutra defines the nature of ignorance as consisting in taking anything that is as if it were not or anything or in any unwillingness to accept things as they really are Ignorance is the inability to understand the non eternal character of things around us and believe that they are eternal.

(ii) Egoism: - is the affliction of the mind that mistakenly identifies the soul with the body. Soul is awareness, the power that sees the atma. Body and sense organs are only the instruments of such awareness; they are the power of seeing. Failure to recognize the difference between the soul and body is asmita or egoism.

(iii) Desire: - is thirst for enjoyment and attraction to pleasure. It makes one's mind a slave to one's senses and ultimately prevents one from concentration and meditation.

(iv) Aversion: - is annoyance with pain this can be a feeling of anger, revenge or desire to attack. Aversion is also a form of bondage.

(v) Attachment: - is the will to live, which is the innate quality in all living beings. It is the desire to cling to life.

Sutra No.10-11 of Yogasutra deals with two categories of afflictions namely, subtle afflictions and gross afflictions. Subtle afflictions arise from tendencies or samskaras and they can be removed only when the mind is resolved back into its original cause namely prakriti by establishing again and again that I am not my senses. Gross afflictions are obstacles in their fully developed form like desire and aversion and are removed through contemplation (dhyana).

Sutra No.29 mentions the eight yogic practices called the eight limbs of yoga, the various rules and practices that must be observed in order to clear the mind of its impurities. The eight limbs, enumerated by Patanjali are:-

1) Yama (the various forms of abstention from evil doings)

2) Niyama (the various observances or self-discipline)

3) Asana (posture)

4) Pranayama (control of breath)

5) Pratyahara (withdrawal of the mind from sense objects)

6) Dharana (fixation of attention or concentration)

7) Dhyana (contemplation) and

8) Samadhi (absorption in the atman or full integration of consciousness)

Yama and Niyama represent moral basis of spiritual progress. These are the main concern of another session of this paper. Hence, it need not be discuss here.

\section{Asana (posture)}

Sutra No.45 defines asana as that the posture that is stable and conducive to happiness. The body must be disciplined to assume a posture helpful to concentration. The practice of yogic postures presupposes two things namely, the body should be completely relaxed and two, the participation of mind along with the body posture. 


\section{Pranayama (control of breath)}

Pranayama is the technique of regulating and restraining the function of breathing. It is another method of controlling the mind easily. It consists in the progressive diminishing of the speed of respiration. The function of breathing consists of:

- Inbreathing or inhalation (puraka)

- Out breathing or exhalation (rechaka) and

- Holding the breath (kumbhaka)

Sutra No.49 of Yogasutra defines pranayama as the intervals between inhalation and exhalation and exhalation and inhalation must be slowly increased, not simultaneously.

\section{Pratyahara (withdrawal of the senses)}

Pratyahara is the fifth of the eight practices of yoga. The purpose of which is to tame the mind through taming the senses. It is the control of senses by calling back the senses from their respective objects. The senses have their own objects. Pratyahara is the ability of the mind to direct the senses and stop the function of the senses according to its command. This can be done by withdrawing the sense of hearing, seeing etc. This guides us to the final three or inner limbs or antaranga sadhana of dharana, dhyana, and samadhi, which are concentration, meditation, and absorption.

\subsection{Vibhutipada}

The third part of the Yogasutra is vibhutipada. Vibhuti denotes manifestation. It discusses about the last three yogic practices of dharana, dhyana, and samadhi. The 56 sutras of this chapter are focused on the accomplishment, called siddhis or powers, which have matured with regular yogic practice. The practices, which have been stressed in the vibhutipada are the three limbs of astangayoga and the amalgamated practice of which is known as samyama. This part deals with the various kinds of knowledge or siddhis that might be obtained by practicing the advanced yogic techniques.

\section{Dharana (fixed attention)}

Dharana means the fixing of the mind to a particular spot or object. The roaring mind is to be tied to a place. Since the senses are by now completely withdrawn, this place does not belong to the external world. Hence spots like heart-lotus, the light in the head or even the seven chakras in the subtle body are mentioned. The point is that the mind must be one pointed and restrained.

\section{$>$ Dhyana (meditation)}

Dhyana is a still superior stage to dharana. It involves not only concentration of the mind on one point but also it involves continuation in the state of dharana. It is uninterrupted flow of mental modes towards the same object. In dhyana the emphasis is on continuity and un-interruption. It is attention on a single point in the form of a continuous flow, steadiness in thought.

\section{Samadhi (fully integrated consciousness)}

The continuation of the process of the mind control is called Samadhi. It can be loosely translated as concentration, absorption, trance etc. When meditation matures, it passes into 
samadhi. It is in samadhi that the spirit is lifted above the world process, and restored to its original status. Samadhi refers to two stages:

- Samprajnata samadhi or samadhi with knowledge: - At this stage, there will be a consciousness of the object. The mind continuous to function, though it is completely absorbed in the contemplation of the object.

- Asamprajnata samadhi: - It is the samadhi without knowledge, there is no consciousness of the object. The objective consciousness disappears and the mind ceases to function since it is concentrated on the self. The spirit is left alone at this stage to experience kaivalya, the ultimate goal.

\subsection{Kaivalyapada}

Kaivalyapada contains 34 sutras and it is the shortest part of the Yogasutra. Patanjali says that, by the practice of yoga, certain supernormal powers are generated. The word kaivalya means perfect isolation of exclusiveness and detachment of the soul from matter and identifying with the supreme spirit. The goal of yogic practice is called kaivalya. This is the emancipation of the soul from contagious and stains of worldly existence of desire and lusts, wealth and pomp, of birth and death. This strictly rational, scientific and psychological approach towards salvation is the core and kernel of yoga philosophy of Patanjali.

\section{Yama and Niyama- A Paradigm for Ecological Virtue Ethics}

Ethical principles of yoga are the systematic collection of rules of conduct guiding behavior. It is an integrated way of life, which includes moral standards traditionally called virtues that may reasonable human beings find in principle acceptable. According to yoga system this practice category is composed under the title of yama and niyama. Ethical principles of yoga are grounded in a profound understanding of the interaction between ourselves and the natural world. In light of this, it seems appropriate for human being to endeavor to conduct ourselves in consonance with the moral principles put forwarded in yoga system. Ethical principles of yoga give importance to self-responsibility for our own life and at the same time for the future generations. It reminds that as an individual, man has great responsibility towards environment.

Yama is essentially the ethical commandments or guidelines deals with underlying principles governing our relation with other human beings, other species in the biosphere, and our surroundings. In strict sense the principles of yama are ethical commandments relating to human behavior in relation to other living creatures and non-living resources. The moral precept of yoga includes the sub concepts of non-violence, truthfulness, non-stealing, celibacy, and nonpossession.

The first yama is non-violence (ahimsa). It is at the very heart of yoga philosophy. It is the principle based on the postulate that all beings are equal. Patanjali used it in the sense of unconditional and universally applicable vow. From ecological point of view, it means never engaging in any form of aggression or violence towards the earth and all of her manifestations. Non-violence is also why yoga promotes vegetarianism. Food has a tremendous influence on our mind. The mind is made from the subtlest portion of food. If the food we eat is impure then our mind and thinking will be impure also. One of the ecological reasons for vegetarianism rest on 
the principle that all life is sacred, and therefore each living species has an equal right to live. Hence man has no right to kill animals and birds. Thus the emphasis on vegetarian diet greatly reduces cruelty to animals and exploitation of natural environment. Another ecological reason for vegetarianism is that the consumption of meat has remarkably deleterious impact on our environment. The contribution of livestock production to climate change is now widely acknowledged. Thus, practice of non-violence by turning to vegetarianism is one way of helping to mitigate the climate change. Environmental crime is also the violence towards environment. It is an illegal act, which directly harm the environment. For example litter is an environmental crime.

Truthfulness (sathya) is the second yama in Patanjali's Yogasutra. This restraint encourages the practitioner to be honest and truthful, a quality that certainly helps to form healthy relationship with human beings and their environment. Abstinence from falsehood means the correspondence of speech and mind to the object intended. Speech and mind are corresponding to what is seen or inferred or heard. It is further say that in so far as there would be a false kind of merit, it would become the worst of evils; therefore, let the yoga way of life consider first of all what is good of all creatures and then speak with abstinence from falsehood. In order for environment to be sustainable, truthfulness needs to be practiced at social, individual and environmental sectors.

In the first of five yamas, non-stealing (astheya) occupies the third position. This precept is clearly stated on the basis of non-violence. Theft, it is said, is unlawful making an object one's own or it is an unauthorized appropriation of things belonging to others. The practice of complete non-stealing is impossible in the world in which we live, but its practice help to reduce human wants to minimum. Non-stealing wants us to face the truth of our basic needs. The observance of non-stealing implies that one should not bother about the acquisition of things to be required in future. Thus, the vow of non-stealing involves the curtailment of wants. One who follows the observance of non-stealing will bring about a progressive reduction of our wants. Stealing is taking an object that one does not really need: we are not aware of our real needs and we increase our needs artificially.

The Yogasutra gives most concrete form of celibacy (brahmacharya). Here, the primary importance is given to its conventional usage and not to its etymological meaning. From ecological point of view one could argue that an uncontrolled sexual power has undesirable effect on the ecosystem. So celibacy has the special meaning in the context of ecology because of the reason that the specialty of this century is that world population entered its exponential phase. The human being therefore, must practice celibacy to keep a proper check on the proliferation of his own species. So there are lesser demands on the ecological assets of the biosphere. Population problem is real and there is a need for controlling the nations birth, the best means towards the desirable goal of family limitation is sexual abstinence. Thus, celibacy is the proper solution for the population problem.

Non-possession (aparigraha) in yoga system means non-possession for something which is not one's own. Non-possessiveness refers to not being selfish, greedy and acquisitive. Nonpossessiveness is an important virtue from ecological point of view. All that exists belongs to nature; it is given to man only for his daily use and not for hoarding it. The ideal of nonpossession require renounce the possession of things not required for use. Nature produces 
enough for our wants day to day. Non-possession means non-dependence on material things. The total abolition of private property is impossible in life and absolute non-possession is an abstraction in its fullness. But we can change our attitude towards nature and natural resources through the practice of non-possession. Limitation of wants could only promote real happiness and contentment.

The observances of self-discipline deals with cultivation of certain virtues i.e., there are selfbased codes of conduct. These observances form the routine of conduct consists of certain good habits, which lead to the development of a personality. It also influence attitude towards environment. The fundamental principles of the observances of self-discipline or the sub concepts come under niyama are cleanliness, contentment, austerity, self-study and devotion.

The principle of cleanliness (sauca) consists of both internal and external cleanliness. The word cleanliness indicates not only the inner purity of thoughts and motives. But it also suggests the purity of environment. After internal cleanliness, external cleanliness comes and since we live in a society it is essential to follow certain rules like keeping our environment clean with the avoidance of littering in public places, refraining from spitting on the road, and many more. In fact, habits like smoking, chewing tobacco and betel leaves, and spitting on roads and sidewalks are sick heritage handed down. Many public places used for defecation are left messy and stinking, leading to number of diseases. Littering on roads, polluted water bodies and poor sanitation make excellent breeding grounds for creepy, crawly pests. From an ecological perspective, purity is very important because impurity of ecological resources means pollution.

Contentment (santhosa) means to be happy with whatever one has, to enjoy living in the present moment without craving or desiring for anything more. Contentment also brings peacefulness; it refers to both being content as well as peaceful. This principle also has an element of being nonpossessive. Being content is the opposite of being greedy. In a sustainable society, individuals will be satisfied with what they have and not jealous or envious of other people having more. Contentment brings happiness and peacefulness. Every human being seeks peaceful surroundings; some were close to nature in order to escape from today's busy and crowded cities. This is where the ecological dimension of contentment comes into picture. We seek to create peaceful environment in our busy cities through the parks, nature reserves and conservation areas. These surroundings are conducive to the feeling of peacefulness.

Austerity (tapas) means following a process of change and transformation for the better. In yoga there is the process of austerity by which the impurities of the personality are burnt off so that the true essence or personality can manifest itself. Simplicity and high thinking are the characteristics of austerity; it leads to happy and truthful life. It promotes good qualities in human beings such as simple living and high thinking. It protects the people from practicing evil habits, helps to the development of mental perfection and firmness, promotes the quality of selfless service, promotes disciplined life, and leads to creativity and betterment of society.

In yoga system, self-study (svadhyaya) means the analysis and knowledge of our own personality, being aware of our behavior, quality, strength and weakness, in order to know who we are. Process of self-study or self-analysis leads us to a deeper understanding of our nature, personality and thinking pattern. Through the practice of self-study we can see where we are 
making mistakes in our life and rectify things by adjusting and adapting our behavior and thinks to fit in with the environment around us. It is the means to understand how to act in the right way at the right time. From an ecological point of view, this would mean learning about the effects of our actions on the ecosystem.

Devotion (isvarapranidhana) is fifth niyama. It is something different from the normal concept of God. It does not refer to a specific God, here refers to anything that we consider above ourselves. What this niyama encourages is that the practitioner to think that there is something above and beyond themselves. It implies dedication to a Supreme Being or power which controls all things, including ourselves, with the realization that we are not the masters of the earth and the lords of the nature. We are in fact, only one of the projections of nature.

\section{Conclusion}

The ethics of yoga have an utmost importance in the present day scenario mainly because it provides the holistic vision of nature. To implement solutions to the ecological problems requires modification of attitudes towards the environment. It is primarily concerned with man's mode of thinking, attitudes and behavior towards nature. So it is proposed that the ecological issues are so serious that we have to create a fresh approach to human virtue. It includes cultivating a new attitude towards environment, living within ecological limits or developing an authentic respect for nature. One of the measures that could help a great deal to fulfill the need of attitudinal change is to regenerate and rejuvenate ethical principles of yoga based on ecological virtues and propagate them. The ethical principles of yoga offer a systematic framework for understanding the character traits and types of action that cause problems for us and environment. The virtues mentioned in the yoga system are praiseworthy. Its application brings forth an encompassing ecological virtue ethics. The task of ecological virtue ethics is so huge that it has correlated all the basics regarding man and nature. Thus in the context of current ecological issues yoga concern for nature is more relevant than ever. In short, application of ethical principles of yoga in the realm of ecology provides the guide lines for:-

- Not to hold ourselves above other living things and have no right to drive them extinction.

- To limit our off springs because increased population will over burden the earth.

- Not to waste our resources.

- Not to conceal from others the effects we have caused to our action on earth.

- Not to snatch from future generations right to live in a clean and safe planet by impoverishing and polluting it.

- To consume the material goods in moderate amounts so that all may share the earth's precious treasure of resources.

The more closely look at yoga principles, the more clearly they point toward taking action to care for the earth. The implication of ethical principles of yoga in the realm of ecology tells what should not do and what have to do in ecosystem. So the best option in this time of ecological issues is return to ethical principles of yoga. 


\section{References}

[1] Dasgupta S N. (1975).Yoga Philosophy. Vol No: I\&II Chennai: Motilal Banarsidas.

[2] Elide, Miraca.(1964). Yoga Immortality and Freedom. U.S.A: Princeton University Press.

[3] Harris, C E. (1997). Applying Moral Theories. Belmont: Wadsworth.

[4] Hiriyanna, M. (1983). Outlines of Indian Philosophy. New Delhi: Motilal Banarsidas Publishers.

[5] James, George. (1967). Ethical Perspectives on Environmental Issues in India. New Delhi: APH Publishing Corporation.

[6] Jamson, Dale. (2001). A Campanion to Environmental Philosophy. Australia: Blackwell Publishing Company.

[7] Lillie, William. (1967). An Introduction to Ethics. New Delhi: Allied Publishers Pvt. Ltd.

[8] Wood, J. H. (1914). The Yoga System of Patanjali. New Delhi: Bharatiyakala Prakashan.

\section{E-source}

[9] En.wikipedia.org/wiki/yoga-sutras

*Corresponding author.

E-mail address: neelambarineela@ gmail.com 